\title{
New Onset Seizures in Young Adults in Coimbatore Medical College Hospital
}

\author{
P.S.Ramesh ${ }^{1}$, B.Gowrishankar ${ }^{2}$, \\ S.P.Kumaresan ${ }^{3}$, R.Aswinth ${ }^{4}$, Ashwinimetry ${ }^{5}$, S.Aravinda Kumar ${ }^{6}$ \\ ${ }^{1,2}$ Assistant Professor, Department of Medicine, Government Vellore Medical College. \\ ${ }^{3}$ Associate professor, Department of medicine, Government Vellore medical college \\ ${ }^{4,5,6}$ Postgraduate, Department of Medicine, Government Vellore Medical College.
}

\begin{abstract}
Backgroung \& Objectives: Seizures are the one of the common medical disorder encountered in daily medical practice. In developing countries like India, CNS infections like meningitis, tuberculosis, HIV, malaria, cerebrovascular accident contribute significant number of cases. These CNS infections are having variable regional distribution. Etiology of seizures varies in developing countries in compared with developed countries. Hence this study was conducted to analyze the various etiologies of new onset seizures in adults the age group of 18-40 years in this region.

Methods:The present study was conducted in coimbatoremedical college hospital, coimbatore.100 cases of new onset seizures were selected as per the criteria which mentioned in the materials and methods. The etiology was determined by appropriate investigations and neuroimaging including cerebrospinal fluid examination if necessary.

Results: Out of 100 patients $92 \%$ were acute symptomatic seizures. The seizure types were GTCS in $56 \%$ and focal seizures with or without cognitive dysfunction in $26 \%$. Among 100 patients $56 \%$ were males, $44 \%$ were females. CNS infection was the leading cause of seizures which accounted for 30\%, followed by Cerebrovascularaccidents (22\%), miscellaneous (12\%) and metabolic (10\%). In 8\% patients of seizures were idiopathic.Among CNS infection ( $n=30$ ), majority of seizures were due to meningitis accounted for $43.33 \%(13)$, followed by meningoencephalitis 30\% (9), cerebral malariae $6.67 \%$ (2), tuberculoma $13.3 \%$ (4) and neurocysticercosis $6.67 \%$ (2).Among cerebrovascular accidents(n=22), CVT accounted for $49.9 \%$ (11), Haemorrhage for $18.1 \%$ (4), Infarct $13.6 \%$ (3), SAH 9.1\% (2) and SDH 9.1\% (2). (CVT - $10+$ Eclampsia)In metabolic seizures $(n=10) 70 \%$ were because of hypoglycaemia (7). $20 \%$ of seizures were pregnancy related. Conclusion: This study analyzes the etiological spectrum of seizures in this part of the world is different from that described from developed countries and CNS infections account for a significant number of cases.
\end{abstract}

Keywords: New onset seizures, central nervous system infections, Cerebro vascular accidents.

\section{Introduction}

Seizures has been recognized since antiquity and the records of epilepsy going back to the second millennia before Christ. Seizures are the one of the common medical disorders are encountered in daily medical practice. In developing countries like our country ,CNS infections -meningitis, tuberculosis, HIV, malaria, cerebrovascular accident contribute significant number of cases. CNS infections are having variable regional distribution, etiolology also varies in different regions. Etiology of seizures varies in developing countries in compared with developed countries. This study was done to know the etiology of new onset seizures in adults. Seizures begin in adolescence associated with CNS infection, cerbrovascular accident, brain tumors, head trauma and alcohol withdrawl. Electrolyte imbalance, hypo or hyperglycaemia, renal, hepatic failure can occur at any age. Avoidance of precipitating factors and prophylactic therapy with antiepileptic medications may reduce recurrence. Hence early intervention in first adult seizures may reduce recurrence.Cerbral venous thrombosis is common in post puerperal women who presents with severe headache, low-grade fever and seizures.Etiology of seizures can be easily made out in most of the patients. In stroke seizures occur more commonly with hemorrhagic stroke than with ischemic stroke. They also can occur with systemic metabolic conditions like hypoglycemia, hyperglycemia, hyponatremia and alcohol withdrawal.

Seizures can be presenting feature in tubercular meningitis, which is most common type of meningeal infection in India. So this study is done to know the various etiologies of new onset seizures in adults in this region. With the use of radioimaging studies like CT brain, MRI brain and Cerebrospinal fluid analysis for infection like bacterial, viral, tubercular the diagnosis of seizure has become more accurate and has completely changed the course of management. 


\section{Source of data:}

\section{Materials And Method}

100 patients admitted with new onset seizures from coimbatore medical college Hospital, Coimbatore who fulfilled the inclusion and exclusion criteria as mentioned below. Study began on December2012 and ended on September 2013.

\section{Methods of collection of data:}

Patients presenting with history of new onset seizures were included in the study. Patient and eyewitness were interviewed regarding history, and clinical examination was done as mentioned in proforma.The investigationsincluded haemoglobin level, total count, differential count, blood urea, serum creatinine, blood glucose levels, liver function test and estimation of serum electrolytes like sodium, potassium, and calcium.Special investigations like lumbar puncture, serological tests, CT scan brain, EEG were done in selected cases.

\section{Statistical method and software:}

The collected data was analysed using the computer programme Statistical Package for Social Sciences (SPSS 11.0) and Systat 8.0. Microsoft word and Excel have been used to generate graphs, tables etc. Descriptive analysis was used to compute percentage, to calculate Mean and Standard deviation

\section{Inclusion criteria:}

1. Age of patients between 18 to 40 years.

2. Patients presenting with new onset seizures.

\section{Exclusion criteria:}

1. age less than 18 years.

2. age more than 40 years.

3. first episode occurring before 18 years continuing adult period

\section{Results}

CNS Infection is leading cause of seizure, which accounted for $30 \%$ followed by Cerebrovascular Accidents (22\%), Miscellaneous (12\%). In $8 \%$ of the patients cause is Idiopathic. Among CNS infection $(n=30)$ .Majority of seizures were due to Meningitis accounted for $43.33 \%$ (13), followed by Meningoencephalitis $30 \%$ (9), Cerebral Malariae $6.67 \%$ (2), Tuberuloma $13.3 \%$ (4), and Neuncysticercosis 6.67\% (2).Among Cerebrovascular Aaccidents(n=22), CVT accounted for 49.9\% (11), Haemorrhage for 18.1\% (4), Infarct $13.6 \%$ (3), SAH $9.1 \%$ (2) and SDH 9.1\% (2),18\% of seizures were pregnancy related. (CVT - $10+$ Eclampsia)In metabolic seizures $(n=10) 70 \%$ were because of hypoglycaemia $(7)$.

Table1 Distribution of etiologies in patients with seizures

\begin{tabular}{|c|c|c|}
\hline Etiologies & Number $(n=100)$ & $\%$ \\
\hline 1. $\quad$ CNS Infection & 30 & 30.0 \\
\hline Meningitis & 13 & 13.0 \\
\hline Meningoencephalitis & 9 & 9.0 \\
\hline Cerebral malaria & 2 & 2.0 \\
\hline Tuberculoma & 4 & 4.0 \\
\hline Neurocysticercosis (NCC) & 2 & 2.0 \\
\hline 2. Cerebrovascular accidents & & \\
\hline Cerebral venous thrombosis & 11 & 11.0 \\
\hline Haemorrhage & 4 & 4.0 \\
\hline Infarct & 3 & 3.0 \\
\hline SAH & 2 & 2.0 \\
\hline Subdural haemorrhage & 2 & 2.0 \\
\hline Miscellaneous & & \\
\hline Alcohol withdrawal & 4 & 4.0 \\
\hline Chronic Renal Failure & 1 & 1.0 \\
\hline Lupus Nephritis & 1 & 1.0 \\
\hline Hanging & 2 & 2.0 \\
\hline JME & 2 & 2.0 \\
\hline EPC & 2 & 2.0 \\
\hline Metabolic & & \\
\hline Hypoglycaemia & 7 & 7.0 \\
\hline Hyperglycaemia & 1 & 1.0 \\
\hline Hypocalcaemia & 1 & 1.0 \\
\hline Hyponatraemia & 1 & 1.0 \\
\hline
\end{tabular}




\begin{tabular}{|l|l|l|}
\hline 5. Eclampsia & 10 & 10.0 \\
\hline 6. Idiopathic & 8 & 8.0 \\
\hline 7. Poisoning & & \\
\hline Yellow Cow dung powder & 3 & 3.0 \\
\hline OPC & 2 & 2.0 \\
\hline Yellow oleander Poisoning & 1 & 1.0 \\
\hline 8. Tumors & & \\
\hline Glioma & 1 & 1.0 \\
\hline Meningioma & 1 & 1.0 \\
\hline Glioblastoma & 0 & 0 \\
\hline Secondaries & 0 & 0 \\
\hline
\end{tabular}

Table2 Various types of CNS Tuberculosis in patients with seizures

\begin{tabular}{|l|l|l|}
\hline CNS Tuberculosis & Number $(\mathbf{n = 1 2})$ & $\begin{array}{l}\text { \% Among CNS } \\
\text { Tuberculosis }\end{array}$ \\
\hline Meningitis & 6 & 50 \\
\hline Tuberculoma & 4 & 33.33 \\
\hline Meningoencephalitis & 2 & 16.67 \\
\hline
\end{tabular}

Table 3: Various types of Meningitis in patients with seizures

\begin{tabular}{|l|l|l|}
\hline Meningitis & Number $(\mathbf{n = 1 3})$ & \% \\
\hline Tubercular & 6 & 46.16 \\
\hline Viral & 4 & 30.76 \\
\hline Bacterial & 2 & 15.38 \\
\hline Fungal & 1 & 7.7 \\
\hline
\end{tabular}

Table 4: Various types of CVA in patients with seizures

\begin{tabular}{|l|l|l|l|}
\hline \multirow{2}{*}{ Cerebro Vascular Accidents (Cva) } & N=22 & \multirow{2}{*}{ Total (\%) } \\
\cline { 2 - 3 } & Male(\%) & Female(\%) & \\
\hline Infarct & 9.1 & 4.5 & 13.6 \\
\hline Hemorrhage & 13.6 & 4.5 & 18.1 \\
\hline Cvt & 4.5 & 45.4 & 49.9 \\
\hline Sah & 4.5 & 4.5 & 9.1 \\
\hline Sdh & 4.5 & 4.5 & 9.1 \\
\hline
\end{tabular}

Table 5: Metabolic causes in patients with seizures

\begin{tabular}{|l|l|l|l|}
\hline \multirow{2}{*}{ Metabolic } & $\mathbf{N}=\mathbf{1 0}$ & \multirow{2}{*}{ Total (\%) } \\
\cline { 2 - 3 } & Male (\%) & Female (\%) & \\
\hline Hypoglycemia & 50 & 20 & 70 \\
\hline Hyperglycemia & 10 & 0 & 10 \\
\hline Hypocalcemia & 0 & 10 & 10 \\
\hline Hyponatremia & 10 & 0 & 10 \\
\hline
\end{tabular}

Table 6: Various types of Tumours in patients with seizures

\begin{tabular}{|l|l|l|l|}
\hline \multirow{2}{*}{ Tumours } & N=2 & \multirow{2}{*}{ Total(\%) } \\
\cline { 2 - 3 } & Male(\%) & Female(\%) & \\
\hline Glioma & 50 & 0 & 50 \\
\hline Meningioma & 50 & 0 & 50 \\
\hline Metastasis & 0 & 0 & 0 \\
\hline Glioblastoma & 0 & 0 & 0 \\
\hline
\end{tabular}

Table 7: Various types of Poisoning in patients with seizures

\begin{tabular}{|l|l|l|l|}
\hline \multirow{2}{*}{ Types Of Poisoning } & N=6 & \multirow{2}{*}{ Total(\%) } \\
\cline { 2 - 3 } & $\mathbf{M a l e}(\%)$ & Female(\%) & \\
\hline Yellow Cowdung Powder & 33.33 & 16.67 & 50 \\
\hline Organophosphorus Compound & 33.33 & 0 & 33.33 \\
\hline Yellow Oleander Seed & 0 & 16.67 & 16.67 \\
\hline
\end{tabular}


Table 8: Miscellaneous Causes for seizures

\begin{tabular}{|l|l|l|l|}
\hline \multirow{2}{*}{ Miscellaneous } & $\mathbf{N}=\mathbf{1 2}$ & \multirow{2}{*}{ Total (\%) } \\
\cline { 2 - 3 } & Male (\%) & Female (\%) & \\
\hline Alcohol withdrawal & 33.33 & 0 & 33.33 \\
\hline CRF & 8.33 & 0 & 8.33 \\
\hline Lupus Nephritis & 0 & 8.33 & 8.33 \\
\hline Hanging & 8.33 & 8.33 & 16.66 \\
\hline JME & 16.66 & 0 & 16.66 \\
\hline EPC & 2 & 0 & 2 \\
\hline
\end{tabular}

Table 9: Etiologies According to Sex Distribution

\begin{tabular}{|c|c|c|c|c|c|c|}
\hline \multirow[b]{2}{*}{ Etiology } & \multicolumn{2}{|c|}{$\begin{array}{l}\text { Male } \\
(n=56)\end{array}$} & \multicolumn{2}{|c|}{$\begin{array}{l}\text { Female } \\
(n=44)\end{array}$} & \multicolumn{2}{|c|}{$\begin{array}{l}\text { Total } \\
(n=100)\end{array}$} \\
\hline & No & $\begin{array}{l}\% \text { among } \\
\text { males }\end{array}$ & No & $\begin{array}{l}\% \\
\text { among } \\
\text { females }\end{array}$ & No & $\%$ \\
\hline 1.CNS infection & 18 & 32.14 & 12 & 27.27 & 30 & 30.0 \\
\hline 2.CVA & 8 & 14.28 & 14 & 31.8 & 22 & 22.0 \\
\hline Infarct & 2 & & 1 & & & \\
\hline Haemorrhage & 3 & & 1 & & & \\
\hline CVT & 1 & & 10 & & & \\
\hline SAH & 1 & & 1 & & & \\
\hline SDH & 1 & & 1 & & & \\
\hline 3.Miscellaneous & 10 & 17.86 & 2 & 4.54 & 12 & 12.0 \\
\hline 4.Metabolic & 7 & 12.5 & 3 & 6.8 & 10 & 10.0 \\
\hline 5.Eclampsia & 0 & - & 10 & 22.73 & 10 & 10.0 \\
\hline 6.Idiopathic & 7 & 12.5 & 1 & 2.27 & 8 & 8.0 \\
\hline 7.Poisoning & 4 & 7.1 & 2 & 4.54 & 6 & 6.0 \\
\hline 8.Tumors & 2 & 3.6 & 0 & - & 2 & 2.0 \\
\hline
\end{tabular}

\section{Discussion}

Seizures are the one of the common medical disorders are encountered in daily medical practice In developing countries like our country CNS infections -meningitis ,tuberculosis ,HIV, malaria, cerbrovascular accident contribute significant number of cases. CNS infections are having variable regional distribution, etiolology also varies in different regions. Etiology of seizures varies in developed countries in compared with developed countries. Hence this study was conducted to analyse the various etiologies of new onset seizures in adults the age group of 18-40 years The present study " The study of new onset seizures in young adults "was conducted in Coimbatore medical college hospital ,Coimbatore.Hundred cases of new onset seizures were selected as per the criteria which mentioned in the materials and methods. The observations are compared with the previous studies were done by earlier on seizures.

Age and Sex distribution: Etiology of seizure depends on age, sex, geography. Out of 100 patients , 56 found to be males and 44 found to be females, with a male to female ratio of 1.27: 1 . Majority of males were in 3rd decade and females were in 2rd decade. In a study from United Kingdom by SANDER ${ }^{14}$ et al (1990), $25 \%$ of cases were below the age of 15 years, $51 \%$ of cases in 3rd-4th decade, and $24 \%$ of cases above 60 years. Another study from south India (Hyderabad) which was conducted by NARAYANAN JT and MURTHY JMK ${ }^{70}$ (2007), 36\% of cases were $>60$ years, with mean age of 49 years.In the present study (table-1) patient's age ranged from 18 years to 40 years,

(Patients more than or equal to 18 years, were included in thestudy). Majority of patients were in the age group of $31-35$ years in males $(n=31,31 \%)$ and 21-25 years $(n=19,19 \%) .17 \%$ of the patients identified in the age group of $36-40$ years. $15 \%$ of the patients identified in the age group of 26-30years.In our study majority of patients were younger unlike western studies were many were in older age group. Comparing with study ofNARAYANANJT and MURTHY JMK. More of CVT patients were seen in our study. No difference in male to female ratio was observed. All studies were slightly male predominate.

Etiological spectrum of seizures:

\begin{tabular}{|lll|}
\hline & SANDER et al (1990) & Present study \\
\hline Acute symptomatic seizures & $15 \%$ & $92 \%$ \\
\hline Idiopathic seizures & $62 \%$ & $8 \%$ \\
\hline Remote symptomatic seizures & $21 \%$ & $3 \%$ (post infarct) \\
\hline
\end{tabular}


Idiopathic seizures were most common seizures noted in western population in compared with acute symptomatic in present study.

\section{Conclusions}

From the present study "Study of new onset seizures in young adults" the followingconclusions were made. $1.92 \%$ of cases presented with new onset seizures in which underlying etiologies can be made.

2•Majority of seizures occurred in patients 31-35 years in males, 21-25years in females

3•Etiological spectrum of seizures were varied and included CNS infection,

CVA, Metabolic causes, poisoning , alcohol withdrawal , Tumour.

4.CNS infection and Cerebrovascular accidents accounted for significantnumber of seizures in all the age groups.

5.The most common cause for seizures in CNS infection is Meningitis

6.CVT is an important cause for new onset seizures among young female patients with cerebrovascular diseases

\section{Bibliography}

[1]. Murthy JMK, Yangala R. Acute symptomatic seizures — incidence and etiological spectrum: a hospital-based study from South India. Seizure 1999; 8:162-165.

[2]. Thussu A, Arora A, Prabhakar S, Lal V, Sawhney IM. Acute symptomatic seizures due to single CT lesions: how long to treat with antiepileptic drugs?. Neurol India2002; 50:141-4.

[3]. Prakash C, Bansal BC. Cerebral Venous Thrombosis. J Indian Acad Clin Med2000; 5:55-61.

[4]. Jan Stam. Thrombosis of the Cerebral Veins and Sinus. N Engl J Med 2005;352:1791-8.

[5]. Lourdes V, Linda M. Seizure Disorders in Elderly. Am Fam Physician 2003;67:325-332.

[6]. Bladin, Christopher F, Alexandrov, Andrei V, Bellavance, Andre et al. Seizures After Stroke: A Prospective Multicenter Study. Arch Neurol.2000; 57:1617-1622.

[7]. WHO, Epilepsy: historical overview. Available at:

[8]. http://www.who.int/mediacentre/factsheets/fs168/en/. Accessed August 2007.

[9]. Hounsfield GN. Computerized tranverse axial scanning: Description of system. BrJ Radiol 1976; $46: 1016$.

[10]. Daniel HL. Seizures and Epilepsy. In: Kasper DL, Brawnwald E, Fauci AS, HauserSL, Lango DL, Jameson JL (eds). Harrison's principles of internal medicine, 16 th ed.

[11]. New York, McGraw-Hill, 2005, Vol.2; 348: p 2357-2371

[12]. Carl WB, Martha JM, Timothy AP. Epilepsy. In: Lewis PR (ed). Merritt'sneurology,11th ed. Philadalphia, Lippincott Willams and Wilkins, 2005, p 990-997.

[13]. Sander JW. The epidemiology of epilepsy revisited. Curr Opin Neurol 2003;16:165-170.

[14]. Bitterncourt PRM, Admolekum B, Baruch N. Epilepsy in the tropics I:

[15]. epidemiology, socioeconomic risk factors and etiology. Epilepsia 1996; 37:1121-1127.

[16]. Annegers JF, Hauser WA, Lee JRJ, Rocca W. Incidence of acute symptomatic seizures in Rochester, Minnesota, $1935-1984$. Epilepsia 1995; 36:327-333.

[17]. Sander JWAS, Hart YM, Johnson AL, Shorvon SD. National General PracticeStudy of Epilepsy: newly diagnosed epileptic seizures in a general population. Lancet1990; 336:1267-1271.

[18]. Willam HT, Ronald PL. The Epilepsies. In: Bradley WG, Robert BD, Gerald MF,Joseph J (eds). Neurology in clinical practice, 4th ed. Philadelphia, Elsevier, 2004,Vol.2; 73: p1953-93.

[19]. Commission on Classification and Terminology of the International League Against Epilepsy. Proposal for revised clinical and electroencephalographic classification of epileptic seizures. Epilepsia 1981; 22:489-501.

[20]. Pandian JD, Thomas SV, Santoshkumar B, Radhakrishnan K. Epilepsia partialis continua-a clinical and electroencephalography study. Seizure 2002; 11:437-441.

[21]. Sinha P, Sathischandra P. Epilepsia Partialis Continua over last 14 years:

[22]. experience from a tertiary care center from south India. Epilepsy Res2007;74(1):55-9.

[23]. Heidi LR, Frank WD. Seizures. Neurol Clin 1998; 16(2):257-284.

[24]. Wijdicks EFM, Sharbrough FW. New-onset seizures in critically ill patients. Neurology 1993; 43:1042-1044

[25]. Timothy AP. The Epilepsies. In: Lee Goldman, Dennis A (eds). Cecil Text bookof medicine, 22nd ed. Philadelphia, Elsevier, 2004, Vol 2; 434: p 2257.

[26]. Giroud M, Gras P, Fayolle H. Early seizures after acute stroke. A study of 1640 cases.Epilepsia 1994; $35: 959$ 